\section{Hemoptysis: is it tuberculosis?}

\section{Bhatta DR, ${ }^{*}$ Singh TSK, ${ }^{2}$ Gokhale $S^{3}$}

\begin{abstract}
${ }^{1}$ Department of Microbiology, Manipal College of Medical Sciences, Pokhara, Nepal, ${ }^{2}$ Department of Microbiology, Sikkim Manipal Institute of Medical Sciences, Sikkim, ${ }^{3}$ Department of Microbiology, Manipal College of Medical Sciences, Pokhara, Nepal
\end{abstract}

*Correspondence to: Mr. Dharm Raj Bhatta, Manipal College of Medical Sciences, Pokhara, Nepal. email: ddharma2039@gmail.com, Tel. No.:(+977)-9806669798

\begin{abstract}
INTRODUCTION: Hemoptysis is usually considered as an indication of pulmonary tuberculosis, but may be associated with various other causes. Present study will draw attention towards various causes of hemoptysis other than pulmonary tuberculosis.
\end{abstract}

MATERIALS AND METHODS: This prospective study was conducted between August 2008 to May 2009 in the Department of Microbiology, Sikkim Manipal Institute of Medical Sciences, Gangtok, India. Total of 61 blood stained sputum samples were collected and examined to detect various etiological agents (bacteria, fungi and parasites) by standard techniques. Brief clinical details of patients related to their illness were recorded.

RESULTS: Acid fast bacilli were demonstrated in $29.5 \%$ of cases. Klebsiella pneumoniae, Pseudomonas aeruginosa, Staphylococcus aureus, Streptococcus pneumoniae, Aspergillus niger, Candida albicans and Candida tropicalis were isolated in $8.2 \%, 4.9 \%, 6.6 \%, 1.6 \%, 3.3 \%, 8.2 \%$ and $3.3 \%$ cases, respectively. Patients were clinically diagnosed as pneumonia in $6.5 \%$ cases and carcinoma of lung in $3.3 \%$ of cases.

CONCLUSIONS: Although pulmonary tuberculosis is the major cause of hemoptysis, other causes of hemoptysis need to be excluded. Every case of hemoptysis, if not investigated properly may be misdiagnosed as pulmonary tuberculosis.

KEY WORDS: Hemoptysis, Tuberculosis

Article submitted 29 October. Reviewed 10 November. Author correction 11 November. Final version accepted 30 December 2012 


\section{INTRODUCTION}

Hemoptysis is defined as expectoration of blood from respiratory tract, a spectrum that varies from blood streaked sputum to coughing out large amount of blood. ${ }^{1}$ Definition of massive hemoptysis varies from $100 \mathrm{ml} /$ day to more than $1000 \mathrm{ml} /$ day. $^{2,3}$ Hemoptysis is one of the most dreaded manifestations of cardiopulmonary disease. It is a frightening symptom for patient and often is a manifestation of a significant underlying disease. Expectoration of even a relatively small amount of blood is an alarming symptom and massive hemoptysis can be life threatening event, therefore hemoptysis of any degree needs thorough evaluation. ${ }^{4}$ Hemoptysis is a non specific symptom and can occur in different clinical conditions. Hemoptysis was for centuries regarded as pathognomic of tuberculosis. In India hemoptysis is almost synonymous with pulmonary tuberculosis and patients presenting with this symptom are often prescribed antitubercular treatment without proper workup. $^{5}$

Hemoptysis is a frightening symptom for patients and is a manifestation of significant underlying disease such as bronchogenic carcinoma. Infection is the most common cause of hemoptysis accounting $60-70 \%$ of cases. ${ }^{6}$ Infection causes inflammation and edema of respiratory tree leading to rupture of superficial blood vessels. In a study in United State, bronchitis accounted for $26 \%$ of cases, while pneumonia and tuberculosis each accounted for $10 \%$ of cases. Invasive bacteria (Staphylococcus aureus, Pseudomonas aeruginosa) or fungi (Aspergillus spp.) are the most common infectious causes of hemoptysis. ${ }^{7}$ In India pulmonary tuberculosis is the commonest cause of hemoptysis. ${ }^{8}$

Among the parasitic infections, pulmonary paragonimiasis and echinococcosis are the common causes of hemoptysis. Pulmonary paragonimiasis is clinically and radiologically indistinguishable from pulmonary tuberculosis. Thus the paragonimiasis should be considered as one of the most important cause of hemoptysis especially in North East states in India where both these parasitic diseases are coendemic. ${ }^{9}$

Viruses such as Influenza virus also may cause severe hemoptysis. ${ }^{10}$ Human immunodeficiency virus infection predisposes patient to severe conditions that may produce hemoptysis including pulmonary Kaposi's sarcoma. ${ }^{11}$ Although uncommon, trauma is another possible cause. Blunt trauma may result in hemoptysis, secondary to pulmonary contusion and hemorrhage. In $7-34 \%$ of patient with hemoptysis no identifiable cause was found even after careful evaluation.7,12,13

This study was conducted to find out various causes of hemoptysis and to generate awareness among health care workers about causes of hemoptysis other than pulmonary tuberculosis. One should carefully investigate a case of hemoptysis, if not may lead misdiagnosis and wrong treatment.

\section{MATERIALS AND METHODS}

Study design and the participants: This prospective study was carried out in the Microbiology department, Sikkim Manipal Institute of Medical Sciences, India. Total of 61 blood stained sputum samples were collected from the patients attending Medicine and Chest \& Tuberculosis department of Central Referral Hospital, Gangtok, Sikkim from Aug 2008 to May 2009. Brief clinical details of patients related to their illness were also recorded from Medical Record Department (MRD) including carcinoma of lung. All patients with complaints of expectorating blood in their sputum were included in this study and patients with complaints of gum bleeding were excluded.

Specimen collection: Early morning expectorated sputum samples were collected in dry, wide mouth, leak proof containers. All patients were motivated to collect sputum sample and were instructed to breathe deeply and cough deeply to bring up sputum and spit the sample directly into the containers.

Microscopic Examination: Gram stain of all the sputum samples was performed to observe the number of pus cells, epithelial cells and bacterial agents. Smears of all the sputum samples were stained by Ziehl-Neelsen (ZN) staining method to detect the presence of acid fast bacilli. Potassium hydroxide $(10 \%)$ mount was done to detect the presence of fungal filament and $0.85 \%$ saline mount to detect the presence of parasitic agents.

Culture: For bacterial culture, sputum samples were inoculated on $10 \%$ sheep Blood agar, Chocolate agar and MacConkey agar. Blood agar and Chocolate agar plates were incubated at $37^{\circ} \mathrm{C}$ in candle jar and MacConkey agar plates were incubated at $37^{\circ} \mathrm{C}$ in ambient air for $24-48 \mathrm{hrs}$. Identification was done by standard procedures like colony morphology, Gram stain and biochemical tests. Culture for Mycobacteria was not included in 
this study. For fungal culture, sputum samples were inoculated on Sabouraud's Dextrose Agar. Culture tubes were incubated at $25-30^{\circ} \mathrm{C}$ for four weeks.

Identification was done by colony morphological examination and lactophenol cottonblue wet mount. Candida spps. were identified based on the colony morphology, Gram stain, germ tube test and carbohydrate fermentation tests.

\section{RESULTS}

Out of total 61 patients included in this study, 40 (65.6\%) were male and $21(34.4 \%)$ were female (Table 1). Maximum cases of hemoptysis were recorded in the age group of 21-30 years. Maximum cases of hemoptysis were seen in the month of March. Cough, fever and chest pain were the predominant symptoms. Two cases had carcinoma of lung (3.3\%), while pneumonia was clinically diagnosed in $04(6.6 \%)$ cases (Fig 1).

Out of total 61 samples, $40(65.6 \%)$ samples showed respiratory pathogens whereas $21(34.4 \%)$ samples showed normal upper respiratory tract flora. Acid fast bacilli were demonstrated in 29.5\% of cases. Klebsiella pneumoniae, S. aureus, $P$. aeruginosa and Streptococcus pneumoniae were other isolates. Among the fungal isolates, Candida albicans, Candida tropicalis and Aspergillus niger were mentionable (Table 2). No parasitic agent was found.

\section{DISCUSSION}

Medical reports from various part of the world revealed that the etiological pattern of hemoptysis in the developed countries has changed, with pulmonary tuberculosis becoming less important cause. ${ }^{14}$ However, in India the pattern has not changed. Pulmonary tuberculosis was the most common cause of hemoptysis four decades ago as shown by Rao ${ }^{15}$ in 1960 and is still the leading cause of hemoptysis. Various studies from other developing countries have also shown pulmonary tuberculosis to be the major cause of hemoptysis. ${ }^{16,17}$

Out of the 476 patients with hemoptysis, 352 $(73.9 \%)$ were males and $124 \quad(26.1 \%)$ were females. ${ }^{18}$ Pulmonary tuberculosis was the leading cause of hemoptysis. There were 377 (79.2\%) patients in the pulmonary tuberculosis group, 25 (5.7\%) in the neoplasm group, $19(4.0 \%)$ in the chronic bronchitis group. $18(3.8 \%)$ in the
Table 1. Age and gender wise distribution of samples collected

\begin{tabular}{lccc}
\hline $\begin{array}{l}\text { Age } \\
\text { group(years) }\end{array}$ & Male & Female & Total \\
\hline $11-20$ & 08 & 02 & 10 \\
$21-30$ & 10 & 08 & 18 \\
$31-40$ & 09 & 03 & 12 \\
$41-50$ & 04 & 05 & 09 \\
$51-60$ & 06 & 02 & 08 \\
$61-70$ & 02 & 00 & 02 \\
$71-80$ & 02 & 00 & 02 \\
Total & $40(65.6 \%)$ & $21(34.4 \%)$ & 61 \\
\hline
\end{tabular}

Table 2. Bacterial and Fungal isolates

\begin{tabular}{lc}
\hline Organisms & $\mathrm{n}(\%)$ \\
\hline Bacteria & \\
Acid fast bacilli & $18(29.5 \%)$ \\
Klebsiella pneumoniae & $05(8.2 \%)$ \\
Staphylococcus aureus & $04(6.6 \%)$ \\
Pseudomonas aeruginosa & $03(4.9 \%)$ \\
Streptococcus pneumoniae & $01(1.6 \%)$ \\
Fungi & \\
Candida albicans & $05(8.2 \%)$ \\
Candida tropicalis & $02(3.3 \%)$ \\
Aspergillus niger & $02(3.3 \%)$ \\
\hline
\end{tabular}

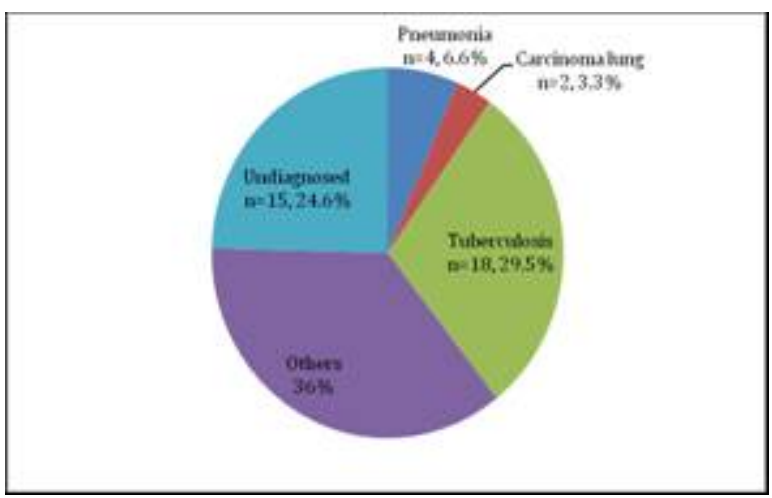

Figure 1. Clinical spectrum of hemoptysis (Others include bacterial \& fungal pathogens other than Mycobacterium tuberculosis)

bronchiectasis group, and 35 (7.3\%) due to other causes. $^{18}$

In present study, out of 61 patients, 40 (65.6\%) were male and 21 (34.4\%) were female. Although pulmonary tuberculosis was the leading cause of hemoptysis (29.5\%), it was less than the above study. Possible reason for this could be the diagnosis of tuberculosis, which was based only on ZN staining, not supplemented by culture of Mycobacteria. However, recent study by Soares Pires F et al. has demonstrated that, $22.2 \%$ cases of 
hemoptysis are associated with pulmonary tuberculosis which is less than our study. ${ }^{19}$ Carcinoma of lung is seen in $3.3 \%$ cases which are almost similar to the observations of Rajendra P et al. ${ }^{18}$

Pulmonary paragonomiasis was reported as major cause of hemoptysis in endemic areas. ${ }^{9}$ Study in Nagaland showed Paragonimus heterotremus as major cause of hemoptysis with $50 \%$ seropositivity. ${ }^{9}$ However, no Paragonimus was found in present study. Crab is not a popular food in Sikkim, but is consumed for medicinal purposes only. None of the patients included in this study had a habit of eating crabs.

Bacterial ( $S$. aureus, S. pneumoniae, P. aeruginosa, $K$. pneumoniae) and Fungal (Aspergillus spp.) agents isolated in this study could be the other possible causes of Hemoptysis.

Fabrice et al reported hemoptysis peaked in March which is similar to the findings of present study. ${ }^{20}$ The seasonal variation of hemoptysis is similar to number of other pulmonary disorders, many of these (exacerbations of bronchiectasis and chronic bronchitis, acute bronchitis or pneumonia) are considered as well established causes of hemoptysis, and could be triggered by winterpredominant respiratory pathogens. ${ }^{21,22}$

The diagnosis of pulmonary tuberculosis in this study was based on demonstration of AFB in sputum. No attempt at culture of Mycobacteria was done. This could be a reason for lower rate of tuberculosis.

\section{CONCLUSION}

Hemoptysis is an alarming symptom to the patient and often indicates serious underlying pathology. Hemoptysis of any degree needs careful patient evaluation and sputum examination to rule out causes other than the pulmonary tuberculosis. Present study draws attention to causes of hemoptysis other than pulmonary tuberculosis. Although pulmonary tuberculosis is the most important cause of hemoptysis in India, hemoptysis due to a variety of other causes is not unusual. Awareness should be increased among general physicians about the various etiologies of hemoptysis. Hemoptysis does not always reflect underlying pulmonary tuberculosis. Hence antitubercular treatment should not be started without proper diagnostic workup.

\section{ACKNOWLEDGEMENT}

I would like to thank all the staff of Microbiology department, Sikkim Manipal Institute of Medical Sciences, for their co-operation.

CONFLICT OF INTEREST: None to declare.

FINANCIAL INTEREST: None to declare.

\section{REFERENCES}

1. Harrison TR, Braunwald E. Principles of internal medicine, Hemoptysis. 16 $6^{\text {th }}$ ed., New York Chicago San Franciso Lisbon London: Mcgraw-Hill 2005; 207.

2. Bobrowitz ID, Ramakrishna S, Shim YS. Comparison of medical v surgical treatment of major hemoptysis. Arch Intern Med 1983;143:1343-1346.

3. Corey R, Hla KM. Major and massive hemoptysis: Reassessment of conservative management. Am J Med Sci 1987;294:301-309.

4. Johnsan IL. Manifestation of hemoptysis, Postgrad Med 2000;112:101-13.

5. American Thoracic Society. The management of hemoptysis. Am Rev Respiratory Dis 1996;93:471-474.

6. Harrison TR, Braunwald E. Hemoptysis In: Harrison's Principles of internal medicine, $15^{\text {th }}$ ed., New York: Mcgraw-Hill; 2001;203-6.

7. Reisz G, Stevens D, Boutwell C, Nair V. The causes of Hemoptysis revisited. A review of the etiologies of hemoptysis between 1986 and 1985. Mo Med 1997;94:633-635.

8. Arora VK. Practical approach to tuberculosis, hemoptysis in tuberculosis, $1^{\text {st }}$ ed., New Delhi: Jaypee brothers 2006;80-88.

9. Singh TS, Mutum SS, Razaque MA. Pulmonary paragonimiasis: clinical features, diagnosis and treatment of cases in Manipur. Trans R Med Hyg 1986;80:967-971.

10. Bond D, Vyas H. Viral pneumonia and hemoptysis. Crit Care Med 2001;29:2040-2041.

11. Nelson JE, Forman M. Hemoptysis in HIV-infected patients. Chest 1996;110-737-43.

12. Set PA, Flower CD, Smith IE, Chan AP, Twentyman OP, Shneerson JM. Hemoptysis: comparative study of the role of CT and fiberoptic bronchoscopy. Radiology 1993;189:677-680.

13. Herth F, Ernst A, Becker HD. Long term outcome and lung cancer incidence in patients with hemoptysis of unknown origin. Chest 2001;120:1592-1594.

14. Bid Well, JL, Pachner RW. Hemoptysis: diagnosis and management. Am Fam physician 2005;72:1253-1260.

15. Rao PU. Hemoptysis as a symptom in chest clinic. Indian J Chest Dis 1960;2:219.

16. Abal AT, Nair PC, Cherian J. Hemoptysis: aetiology, evaluation and outcome-a prospective study in a thirdworld country. Respir Med 2001;95:548-552.

17. Stebbings AE, Lim TK. Cause, treatment and outcome of patients with life-threatening hemoptysis. Singapore Med J 1999;40:67-69.

18. Prasad R Garg R, Shinghai S, Srivastava P. Lessons from patients with hemoptysis attending a chest clinic in India. Ann Thrac Med 2009;4:10-12. 
19. Soares PF, Teixeira N, Coelho F, Damas C. Hemoptysis-etiology, evaluation and treatment in a university hospital. Rev Port Pneumol 2011;17:7-14.

20. Boulay F, Berthier F, Sisteron O, Gendreike Y, Blaive B. Seasional variation in cryptogenic and noncryptogenic hemoptysis hospitalization in France. Chest 2000;118:440-444.

21. Johnston SL, Pattemore PK, Sanderson G, et al. The relationship between upper respiratory infections and hospital hospitalizations for asthma: a time-trend analysis. Am J Respir Crit Care Med 1996;154:654-660.

22. Dales RE, Schweitzer I, Toogood JH, et al. Respiratory infections and the autumn increase in asthma morbidity. Eur Respir J 1996;9:72-77.

\section{Citing this article}

Bhatta DR, Singh TSK, Gokhale S. Hemoptysis: Is it Tuberculosis? Int J Infect Microbiol 2012;1(2);6367. 